\title{
Experimental Study on the Effect of Increase in Splenic Blood Flow upon the Portal Pressure
}

\author{
Toshio Sato, Kenji Koyama \\ Kenichi Watanabe and Shunichi Kimura \\ Department of Surgery (Prof. T. Maki), \\ Tohoku University School of Medicine, Sendai
}

\begin{abstract}
The changes of portal pressure were studied in adult mongrel dogs, while splenic blood flow was let increase in five steps from 0 to $350 \mathrm{ml} / \mathrm{min}$. When intrahepatic portal circulation was left intact, there was no appreciable change in the portal pressure concomitant with changes of splenic blood flow, but in dogs with obstruction of intrahepatic portal branches by silica particles, increase in splenic blood flow caused a marked elevation of the portal pressure. The role of the increase in splenic blood flow and the obstruetion of intrahepatic portal branches in the pathogenesis of portal hypertension in idiopathic splenomegaly was diseussed.
\end{abstract}

In regard to the pathogenesis of portal hypertension, a number of investigators support the view that it is the result of 'passive congestion' of the portal system caused by cirrhosis of the liver or obstruction of extrahepatic portal vessels. According to this concept, splenomegaly which is frequently seen in association with portal hypertension is also nothing but a manifestation of congestion of the portal system.

Studies in recent years, including detailed histologic examinations of the enlarged spleen, the observation of cases in which portal hypertension is present without liver cirrhosis or extrahepatic portal obstruction and the observation that portal hypertension is sometimes accompanied with splenic arteriovenous fistula, have given rise to the opinion that an increased blood flow into the portal system is an important factor in the pathogenesis of portal hypertension.

In a previous publication ${ }^{2}$ we have emphasized that portal hypertension in idiopathic splenomegaly (so-called Banti's syndrome) can be best explained as a consequence of the combination of two factors: An increase in splenic blood flow and obstruction of intrahepatic portal branches. In the present study, an attempt was made in dogs to determine experimentally under what condition an increase of splenic blood flow influences the pressure.

Received for publication, January $30,1969$. 


\section{Materials and Methods}

Experiments were performed on 20 adult mongrel dogs weighing 17 to $20 \mathrm{~kg}$. The animal was laparotomized under penthobarbital anesthesia. The splenic artery together surrounding nerves was eut at about $2 \mathrm{~cm}$ toward the spleen from its junction whith the celiae artery and a cannula of $2 \mathrm{~mm}$ in diameter was inserted into it. Another cannula, with a diameter of $7 \mathrm{~mm}$, was inserted into the right femoral artery which had been exposed and the two cannulae were connected with each other by means of a siliconized vinyl tube with a diameter of $10 \mathrm{~mm}$. A roller-pump* was placed between the two cannulae (Fig. 1).

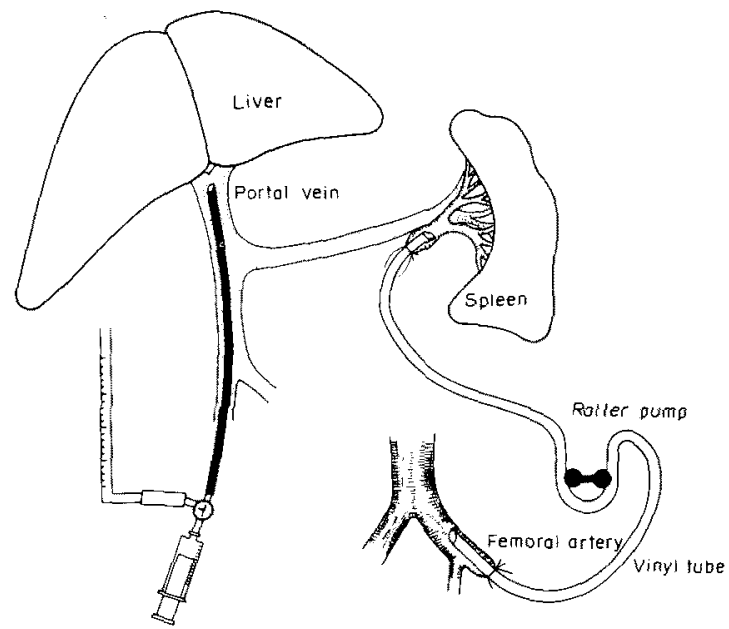

Fig. 1. Schema of splenic perfusion.

The pump was so adjusted by changing its rotation that splenic blood flow could be changed in five steps of $0,100,200,300$, and $350 \mathrm{ml} / \mathrm{min}$. A tube with a diameter of $1 \mathrm{~mm}$ was inserted into the portal trunk through a branch of the superior mesenteric vein for both measurement of the portal pressure and injection of silica particle suspension $f$ to obstruct the intrahepatic portal vessels, $1 \mathrm{~g}$ of silica particles being suspended in $40 \mathrm{ml}$ of heparinized normal saline. Another cannula was inserted into the left femoral artery for a continuous measurement of the arterial pressure during the experiment.

The animals were divided into two groups and one of the groups served as the control. In the control group, splenic blood flow was gradually increased in five steps as described above, and the portal pressure at each step was recorded.

In the second group, while the splenie blood flow was held at $0,2.5 \%$ silica suspension was injected through the catheter into the portal trunk. The portal pressure was measured each time when $10 \mathrm{ml}$ of the suspension was injected, and the injections were repeated until a stable portal pressure of 150 to $170 \mathrm{~mm} \mathrm{H}_{2} \mathrm{O}$ was obtained. When $60-70 \mathrm{ml}$ of the silica suspension were injected, many intrahepatic portal branches were obstructed, as shown in Fig. 2 and stable portal pressure was established. Splenic blood flow was then gradually increased and the corresponding changes in the portal pressure were continuously recorded. In order to check reproducibility of the results, splenic blood flow was reduced after its maximum value was attained and inereased again to the maximum level, while measuring the portal pressure all the time.

* Manufactured by Natsume Co., Osaka, Japan.

$\uparrow$ Wakogel Q-22 Mesh through 200, obtained from Wako-Junyaku-Kogyo Co, Osaka, Japan. 


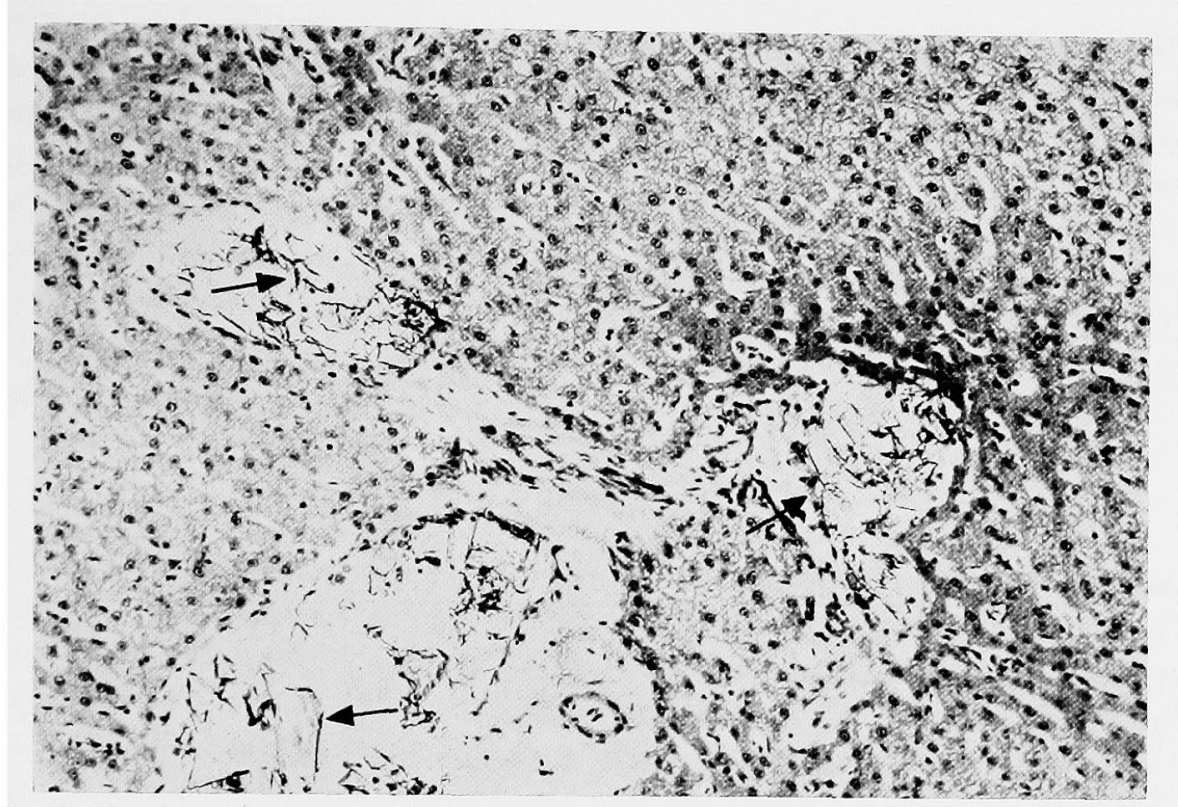

Fig. 2. Histology of the liver after injection of $2.5 \%$ silica suspension portal branches are partially obstructed by silica particles.

\section{Results}

\section{1) Control group}

When the splenic blood flow was 0 , the portal pressure was 110 to $130 \mathrm{~mm}$ $\mathrm{H}_{2} \mathrm{O}$. There was no appreciable change in the portal pressure when splenic blood flow was increased to $100 \mathrm{ml} / \mathrm{min}$. When it was increased to $200 \mathrm{ml} / \mathrm{min}$, the portal pressure increased by 5 to $6 \mathrm{~mm} \mathrm{H} \mathrm{H}_{2} \mathrm{O}$. Even when splenic blood flow was increased to $350 \mathrm{~mm} \mathrm{H}_{2} \mathrm{O}$, the increase in the portal pressure was only 10 to $15 \mathrm{~mm} \mathrm{H} \mathrm{H}_{2} \mathrm{O}$ in most of the time, amounting $30 \mathrm{~mm} \mathrm{H}_{2} \mathrm{O}$ at the maximum. As shown in Table 1 and Fig. 3, the increase in the portal pressure remained below

TABLE 1. Change of portal pressure in control dogs

\begin{tabular}{|c|c|c|c|c|c|c|c|}
\hline \multirow{2}{*}{ Dog No. } & \multirow{2}{*}{\multicolumn{2}{|c|}{$\begin{array}{l}\text { Body weight } \\
\text { and sex }\end{array}$}} & \multicolumn{5}{|c|}{ Portal pressure $\left(\mathrm{mm} \mathrm{H}_{2} \mathrm{O}\right)$} \\
\hline & & & $0^{*}$ & $\mathrm{I}^{*}$ & II* & III* & $I V^{*}$ \\
\hline 1 & $15 \mathrm{~kg}$ & $?$ & 120 & 120 & 125 & 130 & 130 \\
\hline 2 & 13 & \& & 105 & 105 & 105 & 110 & 110 \\
\hline 3 & 14 & $\delta$ & 110 & 110 & 120 & 130 & 130 \\
\hline 4 & 13 & f & 110 & 115 & 115 & 120 & 130 \\
\hline 5 & 14 & $\delta$ & 110 & 120 & 120 & 120 & 120 \\
\hline 6 & 16 & f & 115 & 120 & 125 & 120 & 130 \\
\hline 7 & 17 & 8 & 130 & 130 & 120 & 125 & 130 \\
\hline 8 & 16 & $\hat{\jmath}$ & 120 & 125 & 120 & 130 & 140 \\
\hline 9 & 18 & ? & 110 & 115 & 120 & 120 & 130 \\
\hline 10 & 19 & $\hat{\jmath}$ & 120 & 120 & 130 & 135 & 145 \\
\hline
\end{tabular}

* Splenic blood flow

0: $0 \mathrm{ml} / \mathrm{min}$. I: $100 \mathrm{ml} / \mathrm{min}$. II: $200 \mathrm{ml} / \mathrm{min}$. III: $300 \mathrm{ml} / \mathrm{min}$. IV $: 350 \mathrm{ml} / \mathrm{min}$. 


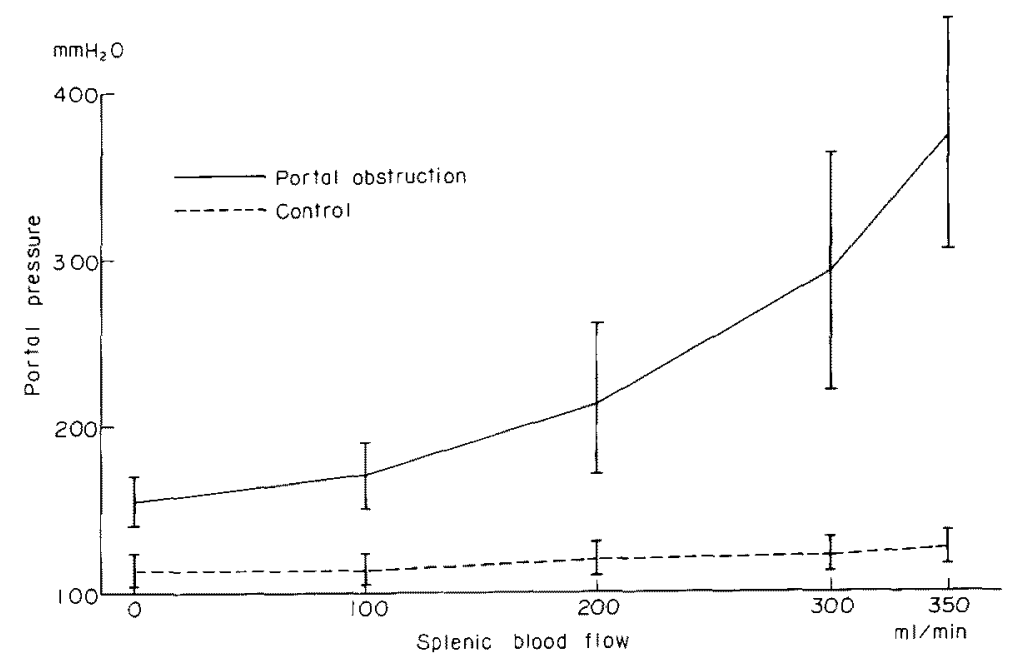

Fig. 3. Relation between portal pressure and splenic blood flow in control and in portal branch obstruction.

$30 \mathrm{~mm} \mathrm{H_{2 }} \mathrm{O}$ as splenic blood flow was increased from 0 to $350 \mathrm{ml} / \mathrm{min}$ in the control group. Besides, there was no appreciable change in the arterial pressure or in the size of the spleen as splenic blood flow was changed.

\section{2) Portal obstruction}

The injection of silica suspension caused intrahepatic portal obstruction and maintained the portal pressure stable at 150 to $170 \mathrm{~mm} \mathrm{H}_{2} \mathrm{O}$, while splenic blood How was 0. As splenic blood flow was increased to $100 \mathrm{ml} / \mathrm{min}$, there was an increase in the portal pressure by 10 to $15 \mathrm{~mm} \mathrm{H} \mathrm{H}_{2} \mathrm{O}$. When splenic blood flow was increased to $200 \mathrm{ml} / \mathrm{min}$, the portal pressure rose by $30 \mathrm{~mm} \mathrm{H}_{2} \mathrm{O}$ at the minimum and $90 \mathrm{~mm} \mathrm{H}_{2} \mathrm{O}$ at the maximum. When splenic blood flow was increased to $300 \mathrm{~m} / \mathrm{min}$, the increase in the portal pressure amounted to $50 \mathrm{~mm} \mathrm{H}_{2} \mathrm{O}$ at the

TABLE 2. Change of portal pressure in dogs with portal branch obstruction

\begin{tabular}{|c|c|c|c|c|c|c|c|}
\hline \multirow{2}{*}{ Dog No. } & \multirow{2}{*}{\multicolumn{2}{|c|}{$\begin{array}{l}\text { Body weight } \\
\text { and sex }\end{array}$}} & \multicolumn{5}{|c|}{ Portal pressure $\left(\mathrm{mm} \mathrm{H}_{2} \mathrm{O}\right)$} \\
\hline & & & $0^{*}$ & $I^{*}$ & II* & III* & IV* \\
\hline 11 & $15 \mathrm{~kg}$ & 8 & 160 & 190 & 220 & 260 & 300 \\
\hline 12 & & 3 & 150 & 160 & 300 & 330 & 370 \\
\hline 13 & 15 & \& & 145 & 165 & 175 & 220 & 310 \\
\hline 14 & 17 & $\delta$ & 170 & 190 & 260 & 340 & 390 \\
\hline 15 & 14 & ? & 145 & 175 & 200 & 350 & 375 \\
\hline 16 & 19 & 3 & 160 & 180 & 240 & 360 & 440 \\
\hline 17 & 17 & P & 155 & 185 & 250 & 320 & 390 \\
\hline 18 & 16 & 3 & 150 & 170 & 250 & 300 & 320 \\
\hline 19 & 20 & $\delta$ & 160 & 165 & 245 & 290 & 310 \\
\hline 20 & 17 & ? & 165 & 180 & 200 & 255 & 315 \\
\hline
\end{tabular}

* Splenic blood flow

0: $0 \mathrm{ml} / \mathrm{min}$. I: $100 \mathrm{ml} / \mathrm{min}$. II: $200 \mathrm{ml} / \mathrm{min}$. III. $300 \mathrm{ml} / \mathrm{min}$. IV: $350 \mathrm{ml} / \mathrm{min}$. 
minimum and $190 \mathrm{~mm} \mathrm{H}_{2} \mathrm{O}$ at the maximum, and it was $140 \mathrm{~mm} \mathrm{H}_{2} \mathrm{O}$ at the minimum and $260 \mathrm{~mm} \mathrm{H}_{2} \mathrm{O}$ at the maximum when splenic blood flow was increased to $350 \mathrm{ml} / \mathrm{min}$. As is shown in Table 2 and Fig. 3, the portal pressure was elevated as splenic blood flow was increased, and the rate of the increase in the portal pressure was more pronounced when splenic blood flow exceeded 200 $\mathrm{ml} / \mathrm{min}$. There was no appreciable change in the arterial blood pressure or in the size of the spleen with the change of splenic blood flow. Reproducibility of the portal pressure changes was proved by repeated changes of splenic blood flow in the manner described above.

\section{Discussion}

In previous publications, we have reported on the results of measurements of splenic bood flow in idiopathic splenomegaly (Banti's syndrome) by means of dye dilution $^{2}$ and histometric ${ }^{3}$ methods. It was revealed that in idiopathic splenomegaly splenic blood flow was markedly increased to 500 to $1,500 \mathrm{ml} / \mathrm{min}$ in comparison with the value of 250 to $300 \mathrm{ml} / \mathrm{min}$ in control subjects. It was also found that in patients with increased splenic blood flow the portal pressure was elevated and the fall of the portal pressure after splenectomy was larger. These flndings will suggest that an increase in splenic blood flow is an important factor in the pathogenesis of portal hypertension. Studies supporting this view were reported by Williams et al. ${ }^{4}$ and Ueda et al. ${ }^{5}$

It has also been established, however, that splenectomy does not always reduce the portal pressure to the normal level in patients with splenomegaly accompanied by portal hypertension. It appears, therefore, that, at least in the presence of established portal hypertension, impairment of portal blood flow in the liver also contributes to development of portal hypertension. In order to evaluate this hypothesis, we thought it would be relevant to compare the effect of changes of splenic blood flow upon the portal pressure with and without impairment of portal blood flow. Observations in patients with idiopathic splenomegaly have revealed that splenic blood flow was increased to about $1,000 \mathrm{ml} / \mathrm{min}$, namely 3 to 4 times the normal value. In the present study, likewise, splenic blood flow was increased as much as 3.5 times the normal value in dogs, since splenic blood flow in normal dogs of the body weight used in the present study was around 100 $\mathrm{ml} / \mathrm{min} .^{2}$ Portal blood flow in normal dogs is approximately 20 to $30 \mathrm{ml} / \mathrm{kg} / \mathrm{min}$ that is around 350 to $500 \mathrm{ml} / \mathrm{min} .^{6}$ Consequently, portal blood flow was increased 1.7 to 2 times the normal value in the present experiments. In tho control group with intact intrahepatic portal circulation, there was no appreciablo change in the portal pressure with increase in splenic blood flow. On the othe: hand, it was found in a previous work ${ }^{7}$ that in dogs after splenic ischemia, a 1.7 times increase in splenic blood flow did not cause any change in the portal pressure. These flndings suggest that an increase in the portal flow of this degree is well compensated by normal hepatic circulation and does not cause any portal hyper- 
tension. It is therefore possible that, when the lesion in hepatic tissue in idiopathic splenomegaly is slight, portal hypertension does not develop as the result of an increase in splenic blood flow. Patients in which such a situation is actually present are not infrequently found. ${ }^{8}$

On the other hand, when obstruction of intrahepatic portal branches was produced by silica particles, increases in splenic blood flow of the same degree as in the control animals caused marked increases in the portal pressure. Obstruction of portal branches produced by silica particles in the present study was not strong enough to cause marked elevation of the portal pressure by itself. The portal pressure was elevated by this procedure to 150 to $170 \mathrm{~mm} \mathrm{H}_{2} \mathrm{O}$, when splenic blood flow was 0 , and to 170 to $190 \mathrm{~mm} \mathrm{H}_{2} \mathrm{O}$ when splenic blood flow was at the normal level of $100 \mathrm{ml} / \mathrm{min}$. An elevation of the portal pressure of this degree does not mean portal hypertension at normal splenic blood flow. When splenic blood flow was increased to twice the normal $(200 \mathrm{ml} / \mathrm{min})$, however, the portal pressure was increased above $200 \mathrm{~mm} \mathrm{H}_{2} \mathrm{O}$ in 5 of 6 dogs, and a three-fold increase in splenic blood flow (to $300 \mathrm{ml} / \mathrm{min}$ ) brought about an elevation of the portal pressure above $200 \mathrm{~mm} \mathrm{H} \mathrm{H}_{2} \mathrm{O}$ in all of the dogs, or above $300 \mathrm{~mm} \mathrm{H}_{2} \mathrm{O}$ in half the dogs. When blood flow was $350 \mathrm{ml} / \mathrm{min}$ the portal pressure exceeded $300 \mathrm{~mm} \mathrm{H}_{2} \mathrm{O}$ in all the dogs.

As has been reported previously, ${ }^{9}$ in patients with idiopathic splenomegaly extrahepatic collateral circulation and other manifestations of portal hypertension were evident in all the patients with portal pressure exceeding $300 \mathrm{~mm} \mathrm{H}_{2} \mathrm{O}$. It can be surmised, therefore, that the obstruction of intrahepatic portal branches of such a degree as to sustain normal portal pressure so long as splenic blood flow is normal may give rise to typical portal hypertension when splenic blood flow is increased to as much as 3 times the normal. Furthermore, this relationship between the amount of splenic blood flow and portal pressure is very similar to that observed in cases of idiopathic splenomegaly clinically.

Tisdale $^{10}$ et al. reported on 5 cases of portal hypertension without obstruction of the intra- and extrahepatic portal system. The liver of his patients, however, exhibited histologically loss of parenchymal cells and fibrosis, although slight, around the portal vessel. Furthermore, intrahepatic portal branches were poorly visualized in splenoportography in these patients, indicating portal obstruction. Therefore, his assertion that there was no obstruction in the intra- and extrahepatic portal system in these patients might not be sustained so far as intrahepatic portal obstruction without liver cirrhosis is concerned.

Arterial hyperemia followed by marked vascular sprouts in the distal region of central arteries in Banti spleens has been noticed by Ono. ${ }^{11}$ This finding seems to support the authors' concept that arterial factor in the spleen plays an important role in the development of portal hypertension with splenomegaly. Ravenna $^{12}$ also suggested primary lesions of the splenic arterioles as a cause of insufficient control of blood flow.

Splenic arterio-venous fistula is a typical example of the causes leading to 
increased blood flow in the portal system. Johnston and Gibson ${ }^{13}$ have reported on 3 cases of this disease, in 2 of which esophageal varices were present and in one of them the portal pressure was found elevated to $290 \mathrm{~mm} \mathrm{H}_{2} \mathrm{O}$, which was reduced to $190 \mathrm{~mm} \mathrm{H}_{2} \mathrm{O}$ after splenectomy. Absence of cirrhotic changes in the liver in these patients led the above authors to the conclusion that portal hypertension in these patients was due to an increase in portal blood flow. Experiments have been performed by many workers in which increases in portal blood flow was produced by various methods. Tomota ${ }^{14}$ perfused an extracorporeal canine liver and spleen preparation with normal saline and investigated the pressure flow-relationship in the combination of liver and spleen. In this study, he found that more pronounced portal hypertention was produced by the perfusion in a preparation of normal spleen and damaged liver after tetrachlor carbon administration than in one of normal spleen and normal liver even at increased flow. He observed furthermore that increase in the portal pressure was of the same degree in a preparation of an enlarged human spleen and a normal canine liver as in one of a normal canine spleen and liver. Although his studies were performed on preparations of isolated organs perfused with normal saline and the condition was therefore far from physiological, it deserves attention that a combination of the liver and spleen was used including the liver having been subjected to pathologic effects. Shilling et $a l .^{15}$ produced in dogs arterialization of the portal vein by implanting a hepatic artery of less than $4 \mathrm{~mm}$ in diameter into the portal vein. No appreciable increase in the portal pressure was observed in these dogs, portal pressures in 3 of the dogs being 148,165 and $200 \mathrm{~mm} \mathrm{H}_{2} \mathrm{O}$ one and a half years after the operation.

Siderys et al. achieved increase in portal blood flow in two ways. In the first method, ${ }^{16}$ the aorta was directly anastomosed with the splenic vein. In the second method, ${ }^{17}$ side-to-end portocaval anastomosis was made in the first step so that all of the venous return below the liver went into the portal vein, and, in the second step, the aorta was anastomosed with the inferior vena cava below the liver side-to-side. Portal hypertension was produced by both of these procedures. Four weeks after the operation of the first method, the increase in the portal pressure averaged $100 \mathrm{~mm} \mathrm{H}_{2} \mathrm{O}$, and hepatic blood flow at that time was $162 \mathrm{ml} / \mathrm{kg} / \mathrm{min}$ in the average, as compared to $33 \mathrm{ml} / \mathrm{kg} / \mathrm{min}$ before the operation. After the operation of the second method, the portal pressure increased by as much as 160 $\mathrm{mm} \mathrm{H} \mathrm{H}_{2} \mathrm{O}$ and attained the level of $320 \mathrm{~mm} \mathrm{H}_{2} \mathrm{O}$ in one case. In this case hepatic blood flow was also markedly increased to $278 \mathrm{ml} / \mathrm{kg} / \mathrm{min}$, which is a more than 8-fold increase compared with that before the operation. Histology of the liver showed periportal lymhocytic infiltrations and fibrosis of varying degrees in all cases. It is to be noted in these experiments that, because of the direct anaistomosis between the aorta and portal system, the aortic pressure was directly transmitted to the portal circulation and the normal blood pressure gradient was completely distorted. Although direct communication between the artery and portal system as in splenic arteriovenous fistula is present in some cases of portal 
hypertension, this is a rare condition and does not account for the development of portal hypertension in general. In experiments by Siderys et al. a five-fold increase in hepatic blood flow was necessary in order to raise portal pressure by $100 \mathrm{~mm} \mathrm{H}_{2} \mathrm{O}$ in an average after aortoportal anastomosis. In clinical cases of portal hypertension, including idiopathic splenomegaly, a decrease, but not an increase in hepatic blood flow is the rule, and maintenance of hepatic blood flow at $5,000 \mathrm{ml} / \mathrm{min}$ (five times the normal amount) is well beyond the capacity of the cardiac output.

Furthermore, in experiments with arterioportal anastomosis, the increase in blood flow is most likely maximum immediately after the operation and declines gradually with time. In idiopathic splenomegaly, on the other hand, the enlargement of the spleen as well as the increase in portal and splenic blood flow progress gradually with aggravation of the disease leading to elevation of portal pressure. Consequently, there is a fundamental difference in the process of increased blood flow between clinical portal hypertension, especially in idiopathic splenomegaly, and experimental arterio-portal anastomosis. It is not justified to regard these two conditions as the same.

In the present study, arterial blood flow was directed into the portal system not directly but through the spleen, and the increase in blood flow was kept below 3.5 times the normal splenic blood flow. Portal and hepatic blood flow did not exceed twice the normal. As was discussed in the foregoing section, these procedures were effective in reproducing the situation in patients with idiopathic splenomegaly.

As has been discussed in previous reports, ${ }^{1,3}$ splenic arteriolo-sinal shunts are often seen in idiopathic splenomegaly. Since they represent a sort of arteriovenous fistulae, it might be assumed that the experimental condition of the present study using the spleen of normal dogs is not all together identical with clinical condition of idiopathic splenomegaly. However, the direct communications act toward a decrease of the resistance to splenic blood flow. It can be assumed therefore that in idiopathic splenomegaly the effect of increased splenic blood flow upon the portal pressure would be more exaggerated than would be expected from the present study.

No definite conclusion can be drawn from the present study upon the relationship between the increase in blood flow and obstruction of intrahepatic portal branches. In experiments of arterio-portal anastomosis by Shilling et al., ${ }^{15}$ Siderys et al. ${ }^{16,17}$ and Miyao, ${ }^{18}$ dilatation of intrahepatic portal branches with thickened walls and periportal cell infiltration and fibrosis of varying degrees were observed. Rather and Cohn ${ }^{19}$ reported on necrotizing vasculitis of the intrahepatic portal vessel in which obstruction of portal branches was demonstrated. As has been discussed by Ueda et al., ${ }^{5}$ these findings suggest the possibility that in portal hypertension, especially in idiopathic splenomegaly, an increase in blood flow causes obstruction of intrahepatic portal branches.

It is to be pointed out, however, that in experiments of arterio-portal 
anastomosis, an extraordinarily large amount of blood flows into the portal system. The condition is evidently unphysiological and quite different from the clinical condition. It is questionable, therefore, whether the changes of portal pressure observed in the experimental condition can be regarded as corresponding to the process taking place in clinical cases. Consequently, the findings of these experimental studies do not afford conclusive evidence to the view that portal hypertension in idiopathic splenomegaly is a result of increased splenic blood flow.

Imanaga et $a l .^{20}$ described in their studies on hepatic circulation in portal hypertension the condition in which impairment of blood flow was restricted to the intrahepatic portal system as a distinct entity. They have not elucidated the mechanism of impaired blood flow, and their view is not completely in accordance with ours in that they regard the development of splenomegaly as the consequence of passive congestion. We are in agreement with them, however, in that we consider obstruction of intrahepatic portal blood flow to be an important factor in the pathogenesis of portal hypertension. In the present study it was demonstrated that the effect of increase in splenic blood flow for elevating portal pressure was manifest only when obstruction of intrahepatic portal branches was present.

We have held the view ${ }^{21}$ that idiopathic splenomegaly or Banti's syndrome is a manifestation of hepato-splenitis. The same pathogenic factor gives rise to changes in the spleen and at the same time causes fibrosis in the liver. From this viewpoint, we have investigated and reported a positive relationship between obstruction of intrahepatic portal branches and portal pressure. It might be accepted that by intrahepatic portal block with silica particles we have succeeded in producing the same condition within the liver as in idiopathic splenomegaly in which intrahepatic portal block is caused by fibrotic process.

Under the present experimental condition, it was demonstrated that a combination of two factors, an increase in splenic blood flow and obstruction of intrahepatic portal pressure, brought about a marked elevation of portal pressure, while each of the two factors alone caused only a slight rise in the pressure. This finding seems to confirm the above-stated view of ours in regard to the pathogenesis of idiopathic splenomegaly.

\section{References}

1) Koyama, K., Suda, Y., Yamauchi, H., Watanabe, K., Kinura, S., Yamamoto, K. \& Sato, T. Hemodynamics and metabolism of the spleen in Banti's syndrome. Gekat (Jap.), 1967, 30, 787-795.

2) Koyama, K. Hemodynamics of the spleen in Banti's syndrome. Tohoku J. exp. Med., 1967, 93, 199-217.

3) Yamauchi, H. Estimation of blood flow in the Banti spleen on anatomical basis. Tohoku J. exp. Med., 1968, 95, 63-77.

4) Williams, R., Parsonson, A., Somers, K. \& Hamilton, P.J.S. Portal hypertension in idiopathic tropical splenomegaly. Lancet, 1966, 2, 329-333. 
5) Ueda, H., Kitani, K., Kameta, H., Takeda, T., Yamada, H. \& Nagatani, M. Idiopathic portal hypertension (II). Naika (Jap.), 1968, 21, 733-737.

6) Grindlay, J.H., Herrick, J.F. \& Mann, F.C. Measurement of the blood flow of the liver. Amer. J. Physiol, 1941, 132, 479-496.

7) Sato, T., Suda, Y., Koyama, K., Yamauchi, H. \& Yamamoto, K. Changes of weight and hemodynamics of the spleen consequent on circulatory disturbance. Tohoku J. exp. Med., 1968, 96, 267-280.

8) Sato, T., Suda, Y., Kakizaki, G. \& Yamauchi, H. Banti's syndrome without portal hypertension. Tohoku J. exp. Med., 1966, 88, 135-152.

9) Sato, T., Koyama, K., Suda, Y. \& Watanabe, K. Splenoportography in idiopathic splenomegaly (so-called Banti's syndrome). Tohoku J.exp.Med., 1969, 97, 161-174.

10) Tisdale, W.A., Klatskin, G. \& Gleen, W.W.L., Portal hypertension and bleeding esophageal varices. New Engl. J. Med., 1959, 261, 209-218.

11) Ono, K. Pathology of spleen. Saishin-igaku (Jap.), 1953, 8, 745-750.

12) Ravenna, P. Banti syndrome (Fibrocongestive splenomegaly). Arch. intern. Med., $1940,66,879-892$.

13) Johnston, G.W. \& Gibson, J.B. Portal hypertension resulting from splenic arteriovenous fistulae. Gut, 1965, 6, 500-502.

14) Tomota, M. Pathogenesis and pathology of portal hypertension. Nippon Geka Gakkai Zasshi (Jap.), 1956, 57, 974-986.

15) Schilling, J.A., Mckee, F.W. \& Wilt, W. Experimental hepatic-portal arteriovenous anastomoses. Surg. Gynec. Obstet., 1950, 90, 473-480.

16) Siderys, H., Tyson, K.T., Herendeen, T.L. \& Glover, J.L. Experimental augmenta. tion of portal blood flow. Ann. Surg., 1964, 160, 910-918.

17) Siderys, H., Judd, D., Herendeen, T.L., Kilman, J.W. \& Waldhausen, J.A. The experimental production of elevated portal pressure by increasing portal flow. Surg. Gynec. Obstet., 1965, 120, 514-516.

18) Miyao, J. Histopathology of the liver and spleen. Nippon Geka Gakkai Zasshi (Jap.), $1955,56,1169-1193$.

19) Rather, L.J. \& Cohn, R. Some effects upon the liver of complete arterialization of its blood supply. Surgery, 1953, 34, 207-210.

20) Imanaga, H., Yamamoto, S. \& Kuroyanagi, Y. Surgical treatment of portal hypertension according to state of intrahepatic circulation. Ann. Surg., 1962, 155, $42-50$.

21) Sato, T., Kakizaki, G., Suda, Y. \& Saito, Y. On the pathogenesis of Banti's syndrome. Tohoku J. exp. Med., 1964, 83, 375-390. 